$9-2003$

\title{
Developing the Professional Self-Concept: Role Model Construals in Early, Middle, and Late Career Stages
}

Donald Gibson

Fairfield University, dgibson@mail.fairfield.edu

Follow this and additional works at: https://digitalcommons.fairfield.edu/business-facultypubs

\section{Peer Reviewed}

\section{Repository Citation}

Gibson, Donald, "Developing the Professional Self-Concept: Role Model Construals in Early, Middle, and Late Career Stages" (2003). Business Faculty Publications. 2.

https://digitalcommons.fairfield.edu/business-facultypubs/2

\section{Published Citation}

Gibson, Donald. "Developing the Professional Self-Concept: Role Model Construals in Early, Middle, and Late Career Stages." Organization Science 14.5 (Sep-Oct 2003): 591-610.

This item has been accepted for inclusion in DigitalCommons@Fairfield by an authorized administrator of DigitalCommons@Fairfield. It is brought to you by DigitalCommons@Fairfield with permission from the rightsholder(s) and is protected by copyright and/or related rights. You are free to use this item in any way that is permitted by the copyright and related rights legislation that applies to your use. For other uses, you need to obtain permission from the rights-holder(s) directly, unless additional rights are indicated by a Creative Commons license in the record and/or on the work itself. For more information, please contact digitalcommons@fairfield.edu. 


\title{
Developing the Professional Self-Concept: Role Model Construals in Early, Middle, and Late Career Stages
}

\author{
Donald E. Gibson \\ Fairfield University, Charles F. Dolan School of Business, North Benson Road, \\ Fairfield, Connecticut 06430-5195 \\ dgibson@mail.fairfield.edu
}

\begin{abstract}
While previous literature tends to focus on role models as significant other people, particularly in one's early life, this study finds that individuals tend to construe their role models as a selection process of attributes from others throughout their career. I discovered that individuals primarily construe their role models along positive/negative, global/specific, close/distant, and hierarchically superior/peersubordinate dimensions, and that across the career span, the tendency to observe role models did not change. Rather, the emphasis placed on different dimensions of role models changes. Early-stage respondents who are working on creating a viable self-concept were more likely to construe their role models as positive, close, and sources of a range of attributes. Middle- and late-stage respondents were more likely to see their role models as sources of specific, and often negative, attributes. The study suggests that these observed patterns are related to individuals' increasing confidence in their professional self-concept. In early stages, individuals pay attention to role models to create a viable self-concept; in middle stages, they seek to refine their self-concept, and in late stages, they seek to enhance and affirm their self-concept.

(Role Models; Careers; Construal; Self-Concept)
\end{abstract}

Research has long emphasized the importance of role models in socializing individuals to new careers, organizations, and tasks (Bell 1970, Caldwell et al. 1990, Kemper 1968, Krumboltz 1996, Wood and Bandura 1989). As depicted in this research, role models serve a vital function in early career socialization by helping individuals create, experiment with, and define their selfconcept (Bucher and Stelling 1977, Ibarra 1999, Super 1963). By paying attention to a role model's style, traits, and skills, individuals can develop their own (Manz and Sims 1981). Individuals are thought to select significant people-such as supervisors, teachers, and mentorsas role models (Kram 1985, Weiss 1977). The assumption is that these salient others exemplify possible goals which individuals are thought to attend to early in life and career. After such periods, when the self-concept becomes more established, individuals are thought to be less in need of, and thus less attentive to, role models.

In this article, I question two implicit assumptions in the extant literature on role models, thus extending the literature and drawing fresh attention to it. First, few studies have examined how individuals actually select and interpret the attributes of their role models - what a role model is to the individual. Most have focused on what a role model does for the individual, examining the process and strategies of behavioral modeling (Bandura 1986, Ibarra 1999) or the functions a role model can provide (Shapiro et al. 1978, Speizer 1981). By taking this approach, researchers have assumed that role models occupy the prominent positions of teacher, mentor, and supervisor when in fact, individuals may have a range of role models outside these categories (Higgins and Kram 2001, Higgins and Thomas 2001).

Second, it has been assumed that role models are important to individuals solely in their early life and career. The majority of research on role models concerns children and adolescents (see summaries in Bandura 1986, Maccoby and Jacklin 1974, Speizer 1981). Organizational research has focused on people before they enter careers (see the review in Gibson and Cordova 1999) or in early stages of socialization (Bucher and Stelling 1977, Ibarra 1999, Kram 1985, Ostroff and Kozlowski 1992). The age range of sampled participants typically peaks at age 30 , and studies examining individuals after age 40 are nonexistent.

However, there is good reason to think that the importance of role models in individuals' careers does not end at these early ages. Research shows that the self-concept 
may be quite malleable as adults develop beyond their 30s, with such development represented more by ongoing creation, construction, and negotiation after the adolescent years, rather than stasis and coherence (Gergen 1977, Kegan 1982, Markus and Wurf 1987). The developing self-concept has been linked to attending to role models (Kohlberg 1963, Super 1963). This thinking is also consistent with career theory suggesting that an entire organizational career can be "characterized as a socialization process" (Van Maanen and Schein 1979, p. 211), as well as findings that individuals' midcareer stages are often periods of substantial ambiguity and change (Levinson et al. 1978). Such qualities suggest an ongoing developmental process rather than one attenuated after the early years of socialization (Hall 1986).

This qualitative and inductive study examines these assumptions and fosters new research by exploring how individuals construe role models in organizations across the career span. I define "role models" here as person(s) an individual perceives to be similar to some extent, and because of that similarity, the individual desires to emulate (or specifically avoid) aspects of that person's attributes or behaviors. Individuals attend to role models as possible exemplars of the professional skills and personal attributes needed to achieve desired goals. I propose that studying individuals' role models over a longer period provides important clues to understanding how the self-concept develops and extends our knowledge of how organizations shape and direct that development. By "construal" I mean the process by which individuals select role models from other people available in their social context and the meaning attached to such role models and their attributes. I use the term in the same sense that researchers have examined "selfconstruals," which represent how individuals define and view themselves and others, including salient attributes, traits, and skills (Cross et al. 2002). This study examines how individuals construe their role models within a particular organizational context, and identifies the underlying dimensions of those construals. I address two research questions: How do individuals construe their role models, and how do individuals' role model construals change at different points in their organizational career?

\section{Theoretical Background}

How Do Individuals Construe Their Role Models?

The surface meaning of the role model construct is straightforward. It combines the concept of "roles," which may be defined as forms of behavior and sets of activities associated with or expected as part of status positions, such as manager, leader, or teacher (Katz and Kahn 1978), with the concept of "modeling," the psychological matching of cognitive skills and patterns of behavior between a target and an observing individual (Bandura 1986). The study of role models draws on two primary psychological theories. Social learning theory suggests that individuals attend to models who are thought to be helpful in learning new tasks, skills, attitudes, and norms (Bandura 1977, 1986). Identification theory adds the notion that individuals may feel an emotional and cognitive connection (they may identify) with role models they perceive to be similar (Erikson 1985, Kohlberg 1963, Slater 1961). In depicting how individuals construe such models, both theories concur with an approach that includes selection of role models from the individual's social environment, and making sense (meaning) of how a role model can help by observing how the model thinks and acts.

Role model selection has recently been conceived as a social comparison process. When individuals are motivated to self-improve, learn a new role, acquire new skills, or set goals, they may select social referents who inhabit these desired roles or exhibit these desired qualities (Collins 1996). The basis of this referent or role model selection is whether the individual (1) finds a role model relevant to his or her needs and goals, and (2) views the role model's position or expertise to be potentially attainable. If an individual views role models as fulfilling these two qualities, they can provide substantial motivation and inspiration (Lockwood and Kunda 1997). Relevance may be guided by various factors, including similar demographic characteristics like gender and age and social characteristics like experience and background (Kulik and Ambrose 1992). The social environment, however, restricts this search process by making role models more or less available. Some role models will be imposed by the environment (e.g., individuals typically have little choice over who their parents, team members, or supervisors are), and some role models will be self-selected by the individual (Wood 1996).

Whether imposed or self-selected, the individual must then make cognitive "sense" or meaning of these role models by attending to those of the model's attributes that are most relevant to their development (Kelman 1961). This process is akin to cognitive models of person perception (Brewer 1988, Fiske and Taylor 1991). Not all aspects of even an important model are adopted by the individual; rather, the individual actively gleans lessons from a model. I define an individual's "role model construal" as encompassing both the selection and meaning aspects of role models, and define "role 
modeling" as a cognitive process in which individuals actively observe, adapt, and reject attributes of multiple role models.

Defining role models in this way helps to distinguish them from two other developmental agents: behavioral models and traditional mentors (Gibson, in press). Behavioral models are observed to learn specific actions and attitudes (Bandura 1986, Decker 1982). Mentors are persons who provide advice and support to a protégé through an interactive relationship (Higgins and Kram 2001, Kram 1985, Levinson et al. 1978). Unlike behavioral models, role models are observed for broader aspects of a social role rather than more limited task skills, and typically involve greater emotional involvement by the individual (Jung 1986). Unlike mentors, role models are based on the individual's cognitive acceptance of the model, not the role model's actions or a necessary interactive relationship (Bell 1970, Fisher 1988).

\section{How Are Role Models Construed Across the Career Span?}

Views of the Stable Self in Adulthood. Traditional views of individuals' career development are characterized by age-related stages in which the individual explores and then establishes a relatively stable view of self, also called "the self-concept" (Gould 1978, Vaillant 1977). A person's self-concept is a person's image of himself or herself, his or her abilities, interests, needs, values, past history, and aspirations (see Hall 1976, Super 1980). For example, Super's (1963, p. 12) influential model of career development describes life stages from "growth" to "establishment" to "maintenance" to "decline," depicting an emerging self-concept through an individual's identifying with key figures and "reality testing" different roles. In this theory, role models are critical to the growth and exploratory stages when individuals role-play aspects of their self-concept.

An assumption of Super's (1963) model is that the process of self-concept development moves toward stability, and that this ought to occur by the establishment stage, or by age 40 . This model reflects the traditional view in psychology that as a result of intrapsychic and social processes, individuals are endowed by adulthood with "a reasonably stable and enduring conception" of who they are, a stable self-concept (see the summary in Gergen and Gergen 1983, p. 131). As Dalton (1989, p. 100) states, "Most students of individual development include the establishment and stabilization of a sense of self or identity as a crucial dimension of personal development." Since "significant others" or role models are critical contributors to an individual's self-concept
(Erikson 1985), an assumption of a stable self-concept in adulthood suggests a pattern in which individuals attend to role models in early career stages, but that role models would later cease to be important to their development. In fact, the older individual may be expected to be a role model for others. An implication of this traditional view is that one cannot simultaneously be a role model for others and continue to seek role models for oneself.

Challenges to the Stable Self-Concept. Recent theory and research offer three challenges to the notion of the stable self-concept in adulthood. First, investigations of how individuals actually conceive of their selfconcept reveal little stability. Based on their empirical studies of aging adults, Baltes and Carstensen (1991, p. 256) argue that the "traditional idea of self as a largely static, unitary, and monolithic entity" is rapidly changing to a view of self "as a dynamic, multifaceted, and active structure." Theorists such as Kegan (1982, p. 107) argue that adult development is less a monotonic trend toward an independent self than a vacillation between a person yearning for greater independence from others to wanting to be "included, to be a part of, close to, joined with"-that is, more fully integrating one's self with others. Gergen (1977) and Gergen and Gergen (1983) have demonstrated that throughout life individuals exhibit substantial changes in self-conceptions, even in relatively short periods.

A second challenge to the notion of the stable self and its link to role models is the concept of possible selves. "Possible selves" are elements of the self-concept that represent "what we could become, what we would like to become, and... what we are afraid of becoming" (Cross and Markus 1991, p. 231). Possible selves are vivid cognitive images of what individuals hope or fear for their future. They may hope for the rich self, the thin self, or the loved self, and dread the alone and depressed self (Markus and Nurius 1986). Role models are important to creating possible selves, because these selves are constructed by individuals through observing salient others in their social environment. Self-concept development, according to Markus and Nurius (1986, p. 955), is "a process of acquiring and then achieving or resisting certain possible selves," and we would expect, then, that the nature of individuals' possible selves will differ depending on age. In fact, Cross and Markus (1991) found that older and younger individuals differ in their possible selves. Older respondents to their study focused on fewer, but more concrete and attainable, possible selves (both hoped-for and feared) than younger respondents. Younger respondents tended to identify a greater number and diversity of possible selves-with some contradicting each other-suggesting a tendency to try out 
one's potential in many domains. The existence of possible selves throughout life-and the importance of role models in their construction (see Ibarra 1999)—supports the idea of self-concept malleability. The relationship between aging and role models, however, remains to be examined.

A third challenge to the notion of the stable self is that the social roles individuals assume affect their selfconcept (Gecas and Mortimer 1988). By enacting role requirements and role-set relationships in organizations, individuals find themselves partially adapting their selfconcept to the needs of that role (Katz and Kahn 1978, Schein 1978). This suggests that as roles change so do elements of the self-concept (Ashforth 2001). During transitions to new roles, individuals are motivated to seek out role models who can illustrate desired behavior in them (Kemper 1968, Merton 1968, Nicholson 1984). Though research has focused on early career transitions in investigating how role models affect this role-making process (e.g., Hill 1992), there is reason to think that transitions in roles may occur throughout careers, particularly as organizations increase their pace of change in strategy and structure (Huber and Glick 1995). We would expect, then, that altering roles over time will also generate a continuing search for role models.

Role Models as Essential to Constructing the SelfConcept. Ibarra (1999) integrated the possible selves and role transition approaches by emphasizing role models as important in socializing professionals in early career transitions. She argued that individuals observe role models to construct their possible selves; through different modeling strategies, individuals "try out" provisional aspects of their self-concept by imitating the actions of others. This approach echoes that of Bucher and Stelling (1977) in their study of medical students who are "becoming professional," and who, they argue, use selected aspects of role models ("partial" role models) to create and construct their "ideal self." By emphasizing role-modeling strategies in socialization, this research accentuates the link between role models and individuals' self-concept development. The current study adds to this work by exploring whether and how these construals may change in career stages after early transitions, as suggested by those challenging the view of the stable self-concept. While both Ibarra (1999) and Bucher and Stelling (1977) focused on individuals' direct interactions with and imitation of their role models, I look at what attributes of a role model individuals attend to, whether or not they directly interact with a person. This approach fits the social learning view of role models as involving vicarious learning (Bandura 1986), and is intended to capture a wider range of attributes sought from role models. It also may help discover how role models are attended to in later life, when direct imitation may be less likely.

The views of the stable self and the constantly developing self in adulthood suggest two takes on the usefulness and prevalence of role models. The first view suggests that as the self-concept becomes more stable, individuals will pay less attention to role models. This position is well represented in the self-concept literature and validates studies that have predominantly investigated role models early in life and careers. The second view suggests that individuals continuously refine their self-concept, and in this process may seek role models for guidance throughout their careers. However, this second view provides little guidance as to how these role models are construed. We can speculate that individuals will attend to role models in some manner throughout their career. Drawing on the possible selves literature, we would also expect that since people gain a more refined view of their possible selves, the role model attributes they attend to may also become increasingly specific.

In sum, this study considers role models as potentially separable from the behavioral aspects of modeling and the interactive mentor relationships that have dominated previous literature. Based on recent theorizing, I define role modeling as a cognitive process in which individuals adapt and reject attributes of multiple role models. I hope to discover the degree to which this definition coincides with individuals' role model construals, and explore how these potentially change in the course of an organizational career, an idea supported by theory but missing in current empirical research.

\section{Method}

This study assesses qualitative data based on interviews conducted in two professional service organizations: an investment bank ("Investment," $n=22$ respondents) and a management consulting firm ("Consulting," $n=21$ ), with respondents ranging in tenure from six months to 32 years, and in age from 26 to 61 . I began by asking respondents what a role model is for them, and who they would describe as role models. From those descriptions, I generated an aggregate pattern of role models in careers. Both my data gathering and analysis follow an inductive or theory-generating strategy (Glaser and Strauss 1967).

\section{Criteria for Sites}

Professional service firms were selected because previous research suggests that attention is given in these 
settings to socializing participants with a codified set of cultural, behavioral, and attitudinal norms. Thus, observing role models is likely to be a salient activity (Bucher and Stelling 1977, Hill 1992). The two firms were selected for both their similarities and differences. They were similar in that both emphasize the specific cultural values characteristic of "strong culture" firms (Deal and Kennedy 1982). They also carefully selected and retained employees who were highly productive rather than explicitly emphasizing an "up or out" system (turnover averaged 7\% annually in both settings). Both firms had reputations of high desirability in their respective markets and had appeared on "top 100" lists of superior places to work. I point out these cultural and reputation factors because they suggest that most employees were focused on succeeding within these firms, providing a setting in which respondents were at least partially motivated to heed local, as opposed to cosmopolitan, role models.

The two firms are structurally similar in that they share comparable hierarchies, similar size (both greater than 1,000), and similar age (greater than 20 years). The firms differ in terms of their client base and nature of task. While Investment professionals primarily work with clients to manage equity portfolios, Consulting professionals work as advisors to clients on human resource issues in large corporations. These task differences also mean that the content of their cultural values differ. Investment is self-described as an "intense," hard-driving culture, reflecting the values of a bottom-line-oriented Wall Street firm. Consulting places relatively more emphasis on interpersonal respect and fair treatment; here, generating a reputation as a valued advisor is paramount.

\section{Criteria for Respondents}

To assure that respondents represented a breadth of organizational experience, firm tenure is used to indicate career stage. The early, middle, and late career designations I use emerged from respondents' views of important role transitions in these firms (see also Hill 1992, Nicholson 1984). In both firms there were basically four levels of hierarchy, with associate being the entry level for professionals and partner (or principal, in the case of Consulting) being the highest level. Neither firm tended to hire people from the outside into levels higher than associate, meaning that virtually all employees at higher levels had progressed through at least two hierarchical levels and had been with the firm five years or more.

Based on experience in the firm as determining career stage, the final sample consisted of 15 respondents in early career (age, $M=30.6$; tenure, $M=2.7$ years);
15 in middle career (age, $M=38.7$; tenure, $M=$ 10.3 years), and 13 in late career (age, $M=47$; tenure, $M=18.3$ years). ${ }^{1}$ Early- and middle-career respondents were randomly selected from a pool of appropriately tenured people provided by the firm. Late-career respondents were the team leaders at the two sites supplemented with respondents from other offices to increase the number interviewed (partner-level respondents were geographically dispersed and difficult to schedule time with). Research suggesting that gender is relevant in considering how individuals identify with role models prompted me to balance the number of men and women respondents (Ely 1994, Javidan et al. 1995, Kanter 1977). There were 21 men and 22 women in the overall sample; 8 of 15 respondents in the early stage were women, 7 of 15 in the middle stage, and 7 of 13 in the late stage. The gender differences in these data are discussed elsewhere (Gibson and Cordova 1999).

\section{Interview Structure}

This study's data were gathered through 43 in-depth interviews. Prior to the interviews, I tried gaining a "native's view" as much as possible so that the questions would make sense to the organizational insider (Spradley 1979). I interviewed two key informants in each organization first (partners with managerial responsibility and executives responsible for training), discussing the nature of work and career path expectations. Findings from these interviews, published and internal secondary data, and two days of site observation led to a semistructured interview protocol. ${ }^{2}$ The questions focused on people who respondents said they looked to as being helpful in advancing in their current career stage. After respondents talked about these people, I asked interviewees the degree to which they regarded the others as role models. From this line of questioning, I intentionally sought a sense of how respondents perceived people who had been helpful before I introduced the term "role model." Interviews lasted from 40 minutes to two and a half hours, with an average of 55 minutes. All interviews were tape recorded and transcribed.

\section{Data Analysis}

The data analysis is organized around my two primary research questions: How do individuals construe their role models, and how do individuals' role-model construals change at different points in their career? I addressed the first question by assembling the perceptions respondents had of their current role models and investigating the attributes they attended to in those models. I answered the second question by comparing role model attributes cited by respondents in early, 
middle, and late career stages. Transcribed interviews were reduced using a computer program for analyzing qualitative data in three steps. My first step was to isolate role model descriptions in the data. Though respondents sometimes spoke in terms of "learning from many people," and models that were composites of several people (see below), the focus of analysis was 115 stories of actual people identified as role models. My second step was to categorize attributes of the role model(s) described in these stories. At the outset I coded for a variety of aspects, including what respondents sought from their role model in terms of skills or personality, interaction frequency, the role model's organizational location vis à vis the respondent, and whether respondents were satisfied with role model availability. Steps one and two revealed the basic dimensions of respondents' role model construals to answer my first research question. Dimensions were derived by grouping together coded text sections of role model attributes and attempting to generate larger categories capturing their essential elements. I iteratively drew on these data and the research literature to corroborate the emerging dimensions. New dimensions were added if attributes from every respondent's role model could be categorized using that dimension. The third step in my analysis was to compare the attributes cited by respondents at each of the three career stages to address my second question.

Examining respondents' role model attributes revealed four underlying aspects of how they construed their role models. I explore these four below as role model "dimensions." Two can be considered cognitive in the sense of showing how individuals perceive and make meaning of their role models: (1) Respondents construed their role models as having attributes they wanted to pay attention to and possibly emulate; they also construed their role models as having attributes representing behaviors or traits that would hinder development and thus should be avoided. (2) Respondents saw their role models as possessing a variety of attributes (a "package" or global set) to be assimilated; they also construed their role models as possessing very specific attributes. The second two dimensions can be considered structural in that they relate to the role model's location in relation to the respondent: (3) Respondents construed their role models as proximal team members and managers; they also saw their role models as existing outside their immediate group, department, or organization. Finally (4), respondents construed their role models as superior people in the hierarchy; they also saw them as peers and subordinates.

I define and elaborate each of these dimensions below. The dimensions can be considered bipolar continua representing the different ways that respondents construed their role models: with positive and/or negative attributes, sought for global and/or specific attributes, and located close and/or distant, higher in the hierarchy or at equal or lower levels. Following my development of these dimensions, I trained two coders blind to the study's intent to assign codes based on the full sample of role model stories $(n=115)$. Interrater reliability across categories was calculated using Cohen's kappa, a statistic that adjusts percentage of agreement rates to correct for chance agreements (Howell 1992). Overall, reliabilities were acceptable (positive/negative $=0.88$; close/distant $=0.86$; up/across-down $=0.91$ ), with the lowest Cohen's kappa being 0.84 for the global versus specific dimension.

\section{Findings: Role Model Dimensions}

\section{Cognitive Dimensions: Positive Versus Negative}

The majority of respondents, particularly in early stages, readily identified role models who they observed for clues on a variety of issues, including skills they wanted to learn, the professional image they were expected to portray, and aspects of the person they would like to "be" as they gained experience in the organization. A salient distinction respondents drew was between role models who possessed styles, attitudes, or behaviors to which they were attracted and wished to emulate, and role models whose attributes they wished to avoid (see Table 1 for criteria and exemplar quotes). ${ }^{3}$

What Is the Basis of Positive Role Model Attributes? The basis of construing positive role model attributes for respondents was a sense of perceived or desired similarity, a sense that the role model offered relevant task or skill expertise, and a sense that the role model could help the respondent develop as a person. In terms of similarity, respondents spoke positively about role models who exhibited a similar background and style, or who represented similar concerns. "A role model is someone that you look at and see that that's someone that you would like to be like," stated one respondent. "You see them as an example of how you'd like to be able to, either with the firm or with clients, present yourself or be doing exactly the same things that they're doing" $\left(\mathrm{InEaF5},{ }_{479}\right)$. Others noted the importance of attitude or outlook (e.g., "Everything he said was kind of the philosophy that I believed in" $[\mathrm{InEaM6}, 488]$.) and similarity in goals: "You need to see what someone else is doing and how they're doing it as a goal or as an aspiration" $\left(\mathrm{InEaF} 2{ }_{789}\right)$. This orientation to positive attributes is consistent with theories linking positive affect to similarity. Similarity in attitudinal, appearance, and skill dimensions is 
Table 1 Dimensions of Role Models, with Criteria and Example Excerpts

$\begin{array}{ll}\text { Positive Negative } & \text { Negerise }\end{array}$

The respondent refers to attributes of a role model that are attended to and/or sought out for emulation.

"He has just the strongest sense of business, and common sense and people skills, it's just amazing...I don't have to sell him on anything. If there's something we need to do, it's, 'Okay. Go do it. Just let me know how I can help.' ... I certainly think that he's a role model for me... he just has a very strong sense of people and the business" (CoEaF3, 378$)$.

\section{Global}

The respondent refers to a variety of attributes in a model which are attended to and/or emulated, including skills, traits, attitudes, and behaviors.

"Those are the types of people that I personally think are the role models. They care about other people, they're terrific with clients, they are able to encompass the whole spirit of Investment, in the way they deal with others within the firm as well as with clients. Having the integrity and the interpersonal skills as well as the advice and experience that you need. Being able to provide all of that in one package" $\left(\operatorname{InEaM1},_{445}\right)$.

\section{Close}

The respondent refers to a model who is in the same workgroup or department, and/or with whom the respondent interacts with frequently.

"Derek is somewhat senior to me, but we act much more like peers. I look to Derek in many ways as a teacher. He's terrific at generating positive relationships with clients. Derek is wonderful on-people just trust him implicitly. So I learn a lot from Derek in terms of his style and approach to the business" $(\operatorname{InEaM6}, 112)$.

\section{Up}

The respondent refers to a model who is higher in status than the respondent.

"He's responsible for all of human resources in the firm. And I guess since he's a generalist, I feel like he's really a role model for me, because he does the same type of job I do, only at a higher level" (CoEaF4,899).
The respondent refers to attributes of a role model that are attended to and/or sought out as examples of how not to behave in a particular context.

"She's very well respected in terms of work skills and the results that she can get-I greatly respect the results she achieves. I do not like the way she achieves them. She gives a lot of feedback, and it's always negative, l've never heard her utter a word of positive feedback to anyone. It creates a very unpleasant, very tense work experience for those who work with her. And I see little to no balance of life in her life structure. So it's like l'd like to achieve the results she achieves in the exact opposite way she does it" (CoMiF11, $\left.{ }_{413}\right)$.

\section{Specific}

The respondent refers to a single or small set of attributes in a model which are attended to and/or emulated.

"I mean, I do look at people that I admire, another role model of mine is-another person who's been one of my bosses, David Ford, I admire David's ability to-he's very objective, and he's very-he has a very well-developed sense or ability to not show his hand, you know, to be very-not unemotional, but to be very relaxed in tense interchanges. That's something I aspire to. I still get too, I get too heated up, I get too, I show my hand too much, so I mean I would look at somebody like that, and say, and Mark Winkelman does the same thing. I think there are still definitely things I need to develop further" $($ InMiF20, 190 ).

\section{Distant}

The respondent refers to a model who is outside his/her workgroup or department, and with whom the respondent interacts infrequently or not at all.

"He was a very colorful personality; I never worked for him directly, as some people have. And they can tell you more stories about $\mathrm{Cal}$, but you knew when you're in the room with Cal Black, you know he's there. He's one of those kind of guys" $\left(\right.$ CoLaM9, $\left.{ }_{1263}\right)$.

\section{Across/Down}

The respondent refers to a model who is a peer, a subordinate, or who is ambiguous in status (e.g., a client).

"I have a couple people that I report to, but they're doing very different jobs than I am, so I have a couple of the other people that are managing regional offices and I are mutual role models - I learn from them, they learn from me" (InLaM18, $\left.{ }_{676}\right)$. attractive (Byrne 1971). Social comparison theory also suggests that individuals seek similar others as referents because they are informative for making accurate self-assessments and inspirational for achieving selfimprovement (Festinger 1954, Lockwood and Kunda 1997). Perceived similarity between an individual and a role model-and a desire to increase that similarityis also the essential quality of the identification process between individuals (e.g., Kelman 1961, Kohlberg 1963, Slater 1961). In terms of tasks and skills, respondents noted a range of attributes that provided clues to learning (e.g., "He has just the strongest sense of the busi- 
ness and common sense and people skills"; "I watched him because he was a very skillful negotiator"; "They have time management skills"; see Table 3). Observing others who share desired skills has been linked to enhanced performance (Earley and Kanfer 1985) and self-efficacy (Bandura 1977). Finally, respondents noted the self-development benefits of positive role models (e.g., "Those two individuals kind of define my role"; "I could see all the things that I was looking for [in him]"). One respondent succinctly noted, "To me a role model is someone I look at and say, that's what I want to do or that's what I want to be" $\left(\mathrm{CoEaF} 3{ }_{720}\right)$. Individuals seek to become "like" their positive role models because these exemplars can help individuals define who they are as professionals and as people (Bucher and Stelling 1977, Kelman 1961).

What Is the Basis of Negative Role Model Attributes? Respondents also identified role model attributes that were negative: behaviors or attitudes they attended to in others that they sought to avoid in themselves. When initially asked whether they had a role model, most respondents referred to positive role models, but consistent with theory and existing research (e.g., Bucher and Stelling 1977, Merton 1968), a substantial proportion of respondents spontaneously initiated comments about negative ones as well ( 15 of 43 , or $35 \%$ did so; after early interviews suggested that this was an important set of attributes, in later interviews I specifically asked about respondents' perceptions of negative attributes if they did not spontaneously mention them). Negative role model attributes were salient to respondents in two different ways. One was that respondents spoke of primarily positive role models who also exhibited negative traits. As one respondent noted, "I learned an awful lot of the business from John, and I think he would be a role model, even if in some respects (he also exhibited) roles or behaviors that you definitely did not want to acquire" $\left(\right.$ CoMiM9 $\left.{ }_{598}\right)$. The second way respondents talked about negative role model attributes was in the form of particular people who represented a "negative role model" or more extremely, an "antimodel" who exhibited a predominance of negative traits (see Table 1).

The basis of perceived negative traits appeared to be related to three aspects: perceived dissimilarity, actions by a role model perceived to have negative results for the team or the firm, and a desire by respondents to "disidentify" or clearly differentiate the negative role model as belonging to a social out-group. Regarding dissimilarity, respondents identified role model attributes as negative if they did not fit their own style, demeanor, or attitude. "I'd like to achieve the results she achieves in the exact opposite way she does it," noted one (see Table 1). Another noted, "I think one of the reasons I left that group is that there were a lot of people I just didn't feel that that's the kind of characteristics that I personally wanted to possess" $\left(\mathrm{InMiF} 12,{ }_{340}\right)$. This aspect reflects the mirror opposite of attractive similarity-perceived dissimilarity produced a feeling of negative affect.

Regarding actions by a role model, particularly salient in the firms I examined were individuals highly successful by the firm's standards of productivity, but who treated other people in the firm with disrespect. These antimodels reflected negative interpersonal skills. One respondent referred to a "tyrannical type of leader," a person who had "burned through a great number of people," yet "people have to put up with him because he's so talented" (InLaM18, $\left.{ }_{1000}\right)$. Regarding disidentification, respondents also suggested that viewing negative role models helped them define their own self-concept by illustrating what they were not (Elsbach and Bhattacharya 2001). This suggests that negative role models represented a negative social out-group (Merton 1968). One respondent said, "I can learn things from people that I don't like. Even if it's just that I don't want to be like them" $\left(\mathrm{CoLaM} 9{ }_{414}\right)$. Part of disidentification was an implicit fear that they might become like the negative role model: "When they act in particular ways," one respondent noted, "I think I've got to make sure that I'm not doing that" (see Table 5). This tendency reflects the notion of possible selves feared by an individual (Cross and Markus 1991), and suggests that negative role models, though frequently disliked, were nonetheless considered useful for learning.

\section{Cognitive Dimensions: Global Versus Specific}

The global versus specific dimension represents the degree to which respondents construed role models as containing a relatively large set of traits or attended to them selectively for particular traits. ${ }^{4}$ On the global side of this continuum (see Table 1), respondents spoke of role models providing a range of attributes in "one package," including personal traits ("integrity," "care about people"), and organizationally relevant skills ("terrific with clients," "interpersonal skills," "process skills"). The global dimension indicated that the respondent was open to several possible inputs from a role model, from the professional to the personal. On the other end of this continuum, respondents also spoke of role models to whom they attended for very specific traits and skills. For example, the quote in Table 1 indicates that the respondent heeded a particular skill in her role model, 
the "ability to not show his hand," in tense interchanges. This distinction between attending to a wide versus narrow set of traits in a role model has roots in reference group theory. Merton (1968, p. 357) distinguishes between referent individuals who are emulated for a "wider array of behaviors and values," and those who are emulated for "limited segments" of behavior and values. This dimension also reflects more general, social cognitive tendencies in individuals who have been found to perceive others through both a categorical, top-down approach (relying on global schema) and a data-driven, bottom-up approach (relying on specific examples-see Brewer 1988).

A tendency among some respondents (mentioned by 14 of 43 respondents, especially in the middle and late career stages; see below) was to integrate the specific attributes of their role models into a composite that approximated a global role model, albeit a cognitively created one. "There are certain characteristics that I like about a variety of people that I kind of pull in and make my own role model" $\left(\mathrm{CoMiF} 13,{ }_{421}\right)$, noted one respondent. Another stated that she sought to "create a model for myself of what I'd like to be" from multiple role models $\left(\right.$ InMiF14, $\left.{ }_{779}\right)$, while another spoke of creating an "aggregate" of his role models' styles (see Table 5, Quote 10). The notion of forming composite role models is consistent with social learning theory, depicting modeling as a cognitive process in which the individual creates a visual image of how a behavioral model carries out a particular task, and then generalizes from that image to different situations (Bandura 1977, 1986).

\section{Structural Dimensions: Close Versus Distant, Up Versus Across/Down}

The close/distant and up/across-down dimensions represent structural aspects of construing a role model influenced by the particular organizational context facing the individual (Kanter 1977). There are two aspects of structure important here: (1) Whether respondents perceived positive role models to be available in their relevant context, and (2) where they found role models. Though previous studies have noted that role model availability contributes to individual learning and effectiveness (e.g., Bandura 1986, Ely 1994, Thomas 1990), little research has examined what availability means to individuals observing role models, beyond a purported general "need" for them (Speizer 1981). Perceived availability of role models is defined here as the degree to which respondents think there are sufficiently similar others in their environment who they can observe and possibly emulate.
In terms of the structural dimensions, role models could be construed from those who directly interacted with the respondent (including by electronic means, such as e-mail or telephone). I designated these role models as "close." Close role models were cited by respondents as providing vivid examples of task skills, performance standards, and professional styles. Their availability meant that respondents could observe how a role model responded to situations and note performance feedback (Ashford and Cummings 1983). Respondents also had role models who were less available, but were nonetheless salient and visible because they contained attributes specifically sought by the respondent or were considered particularly important by the firm. I designated these role models "distant." In both firms, respondents spoke of organizational heroes (Deal and Kennedy 1982) to whom they paid attention as representing important firm values or who were featured in stories meant to signal approved actions. Leaders of the firms, clients who exhibited unique or exemplary qualities, and members of external organizations were considered by respondents to be distant role models.

Similarly, respondents varied to the degree that they observed role models who were more advanced than they in the organization's hierarchy or who had greater experience, and those who were at peer or lower levels in terms of hierarchy. Variation on this dimension tended to relate to whether respondents were seeking to advance in the organization (in which case they focused on upward role models) or whether they had reached a level where upward advancement was unlikely (in which case they looked to peers or downward for new ways to excel in their current position).

\section{Findings: Dimensions of Role Models by Career Stage}

Table 2 presents data on the percentage of respondents emphasizing different role model dimensions in early, middle, and late career stages. The table shows that respondents construe role models throughout their career, but the relative importance placed on different dimensions changes. The table reveals two overall findings: (1) Early-stage respondents were more likely to construe their role models as possessing global attributes, while middle- and late-stage respondents were more likely to construe specific attributes and skills, and (2) early-stage respondents were more likely to construe their role models as positive, while middle- and late-stage respondents more often construed them as negative. 
Table 2 Coding Results by Career Stage and Role Model Dimensions

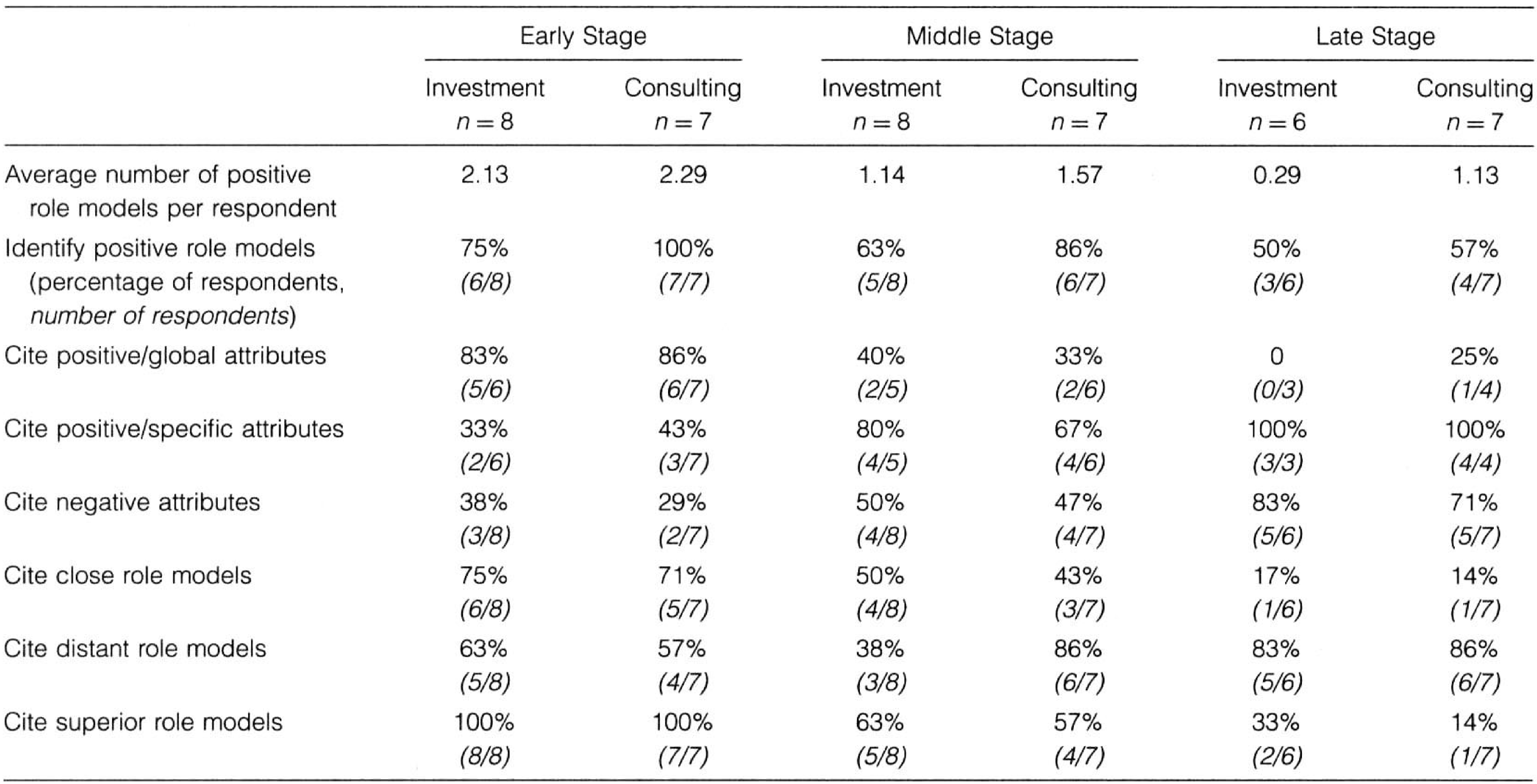

Figure 1 Idealized Model of the Pattern of Attention to Role Models Across the Career Span

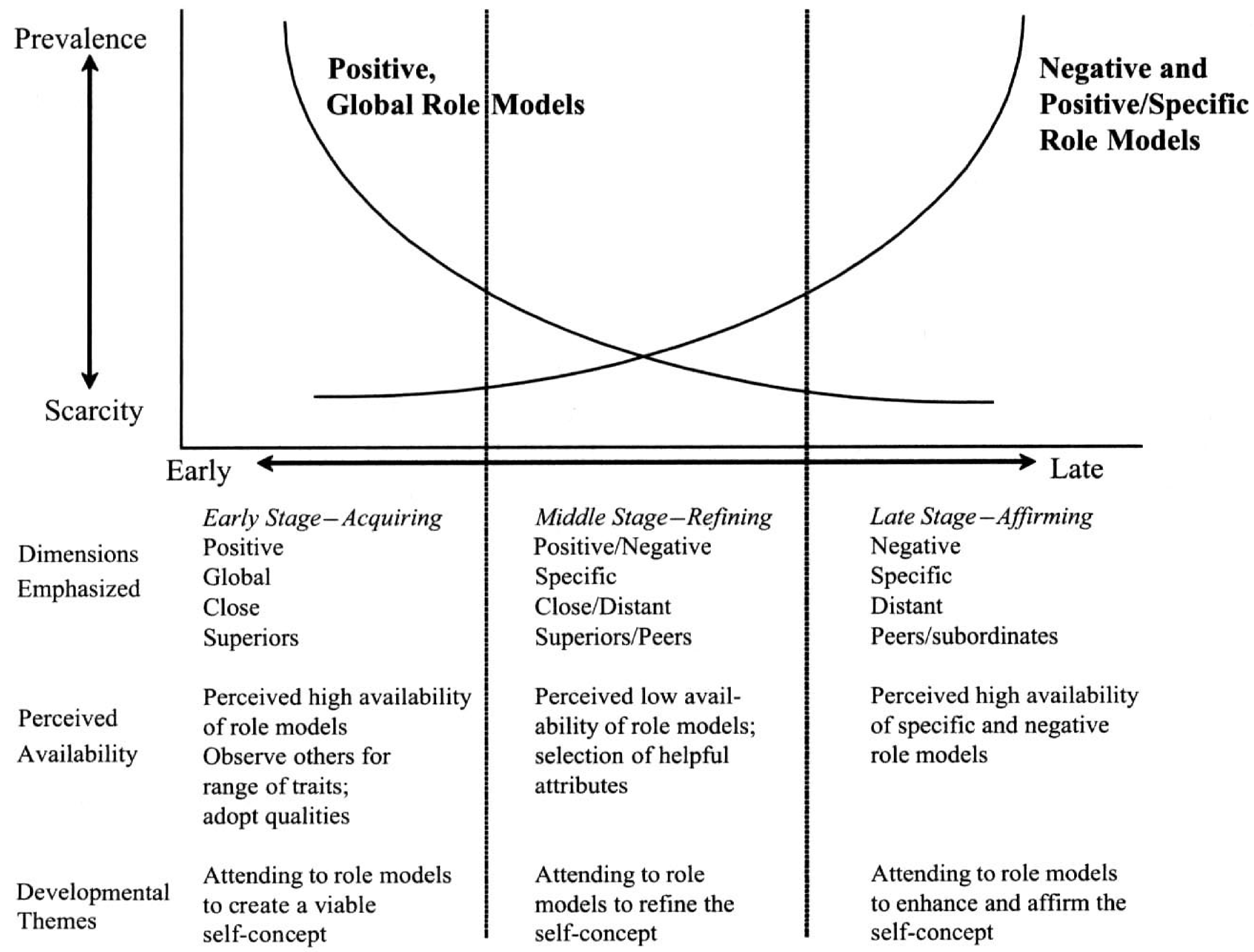


Figure 1 shows an idealized model of the Table 2 data. The model is idealized in that the curves represent the predicted trajectories of individuals' role model construals rather than an exact quantitative representation (see a similar approach in Carstensen et al. 1999). The X-axis reflects time in an individual's career; the Y-axis reflects the prevalence of role model dimensions individuals tend to construe. In the early stage, respondents' construals were aimed at acquiring as much information as possible on both personal and professional issues; they sought a breadth of role model attributes to evaluate themselves and create a viable self-concept and professional identity. In the middle stage, respondents' emphasis was on refining their self-concept by attending to specific role model attributes. They eschewed the notion that there was a "whole person" out there who could serve as a role model. Rather, they interpreted specific lessons derived from both positive and negative models. In the late stage, respondents' role model construals were aimed at affirming their self-concept by attending to negative role models who illustrated aspects they themselves desired to avoid, thus emphasizing their uniqueness. They also sought positive/specific role models from whom they could learn particular skills. In the sections below, I describe each stage with illustrative quotes. For each stage, I organize the findings around (1) the current concerns and goals of the respondent, (2) the role model dimensions characterizing that stage, and (3) respondent perceptions of role model availability.

\section{Early-Stage Role Model Construals}

Current Concerns and Goals. Respondents in the early stage wanted to learn two primary things from their role models: How to perform tasks competently and professionally, and how to fit into their professional role both by matching the characteristics of the organizational culture and by earning the respect of their colleagues. These needs are consistent with the findings of organizational socialization research, emphasizing that participants initially focus on task needs and establishment of their role (Hall 1976, Van Maanen and Schein 1979).

Positive/Global Role Models. Respondents reflected these socialization concerns in their role model construals. In this newcomer stage, respondents most frequently identified role models who fit the traditional mold: They were generally positive models exhibiting a relatively wide range of traits, relatively close to the respondent in terms of proximity and frequency of interaction, and hierarchically superior. As shown in Table 3, respondents observed their role models for a range of skills ("people skills," "process skills"), personality traits ("energetic, hard working"), and organizational norms ("treating people with respect"). In most cases, respondents in these firms identified two to three people-typically supervisors or more experienced members of their work teams-as positive, global role models. Identifying these close role models with global traits was efficient: From one or very few role models, one could observe a variety of traits and adopt those that worked well for the respondent's developing sense of style. Notably, even at this stage, respondents understood that it was important to have multiple role models to view different ways of operating (they averaged 2.21 role models across the two organizations). Multiple role models provided requisite variety: Viewing different behavioral styles and attitudes made it more likely that respondents could assimilate traits and skills that worked for them. These findings map well onto previous research, suggesting that early-stage socialization is aimed at creating a viable self-concept by observing and possibly emulating significant others in the work context (e.g., Schein 1978). The openness indicated by construals of global role models suggests that individuals are actively engaged in the "construction of professional identity" (Shapiro et al. 1978, p. 52).

\section{Middle-Stage Role Model Construals}

Most research on socialization and role models has been applied to the early stage, with the implicit assumption that role models would recede in value as an individual advances in his or her career. This assumption was not borne out in this study. Rather, respondents in the middle career stage tended to: (1) emphasize positive and specific attributes of their role models, (2) emphasize the importance of having role models for task transitions but perceive a paucity of available models, and (3) recognize the development of their own style as fostering selection rather than adoption of role model attributes.

Current Concerns and Goals. Midcareer, for these respondents, was a paradoxical time in which they simultaneously felt established as competent players in their firm, but also faced ambiguity and uncertainty about their future role (see Hall 1986, Levinson et al. 1978, Schein 1978). They were expected at this point to make a transition from team player to business generator, from implementing client relationships begun by others to generating their own, and from being subordinate to others to managing others (see Hill 1992 for a discussion of transitions in professional firms). If they had not made partner (10 of 15 in this sample had not), they had to contend with alternative positions of leadership that were 


\section{Table 3 Example Quotes Characterizing Early-Stage Respondents' Role Models}

Dimensions

Positive/global attributes of role models

Perceived availability-high
(1) "I could see all the things that I was looking for, one, it's a dynamic, driven business, and he's energetic, hard working. Highly moral and ethical in everything he does, in his whole life, so that would roll over to his business" (InEaM4, 336 ).

(2) "I met this guy, Rich Ackley, and (he) blew my socks off because everything he said was kind of the philosophy that I believed in, you know, treating people with respect, working in teams, making a lot of money, having fun. It felt like sports to me, which is what I love...I mean, at first Rich was an image, then you make an effort to get to know this person, then you're lucky enough to go to work for him-he's clearly a guy that becomes an important role model" (InEaM6 ${ }_{488}$ ).

(3) "Those would be the two that come to mind in terms of the impact they have with their clients, they work with very large organizations, they have time-management skills, very good people skills, process skills. Good business judgment-they've just got it under control" (CoEaF3, $\left.{ }_{599}\right)$.

(4) "You work with a lot of people in a national center, you like most if not all of them, but there are key role models. Kevin Cortez, my boss, here has been a role model for consulting style in general, particularly consulting style with senior and older-type executives or directors. And he's been a role model that you kind of build to and say, 'Kevin does have a lot of experience-25 years more than I-but here are things I can watch for and try and emulate.' Lisa Bolter is a couple of years older than I am, and also has a consulting style that works very, very well with clients. Very straightforward, very friendly, very objective. What you see is what you get. That's been something to emulate. Very, very good role model" (CoEaM6, $\left.{ }_{432}\right)$.

(5) "I would say there are a few people that I've looked to as, I viewed (them as) fully competent in their role. And as I look to them, that's what I kind of strive for, and benchmark, see where I was relative to them. Dwayne is running our Los Angeles office and has really taken that office to new heights with the organizations that we're working with. I felt very fortunate to have him as a manager and wanted to emulate how he did his role in account management. He technically knows his stuff. And yet as a manager to me for the last several years he's a very caring individual, cares about people. And the same thing with Dorothy-those two individuals kind of define my role" $(\mathrm{CoEaF1}, 628)$.

(6) "As an individual there are certain characteristics and traits that I really admire. So those people who had sort of a preponderance of those traits, those are the people that I tend to admire. There were a lot of people in New York (the location of orientation training) that I would say were role models... I can probably name 15 people who I consider role models" (InEaM1,213). less well defined. If they had made partner, they had to continue to bring substantial new business to the firm. These sources of ambiguity and continuing exploration were expressed in the way middle-stage respondents construed their role models. Respondents expressed a sense that though they had successfully negotiated earlier stages, they lacked guidance-particularly through visible role models - of what the next career step ought to look like. With increasing confidence in their sense of self, they were better able to discern what specific attributes of role models could help them. However, as time passed, career choices simultaneously became more constricted and potential role models were perceived as less available (see Dannefer 1987). While in the early stage the career trajectory was clear (try to move up), in the middle stage it was less obvious how much future advancement was possible and even whether continued membership in the firm was possible.

Positive/Specific Models Amidst Feelings of Limited Availability. Reflecting these concerns, in this stage respondents were less likely to talk about their role models as an all-encompassing package of traits and skills, and more likely to talk about them as potentially contributing specific attributes. Table 2 indicates that the number of respondents who cited positive and specific attributes of their role models increased in this stage, but the tendency to cite global attributes declined. Role models now were construed as "different people for different things" (Table 4, Quote 1) and emulated for "different styles" (Quote 2). Further, respondents indicated a strategy of creating composite role models, in the sense that they could "get a whole role model out 
Dimensions:

Positive/specific attributes of role models

Perceived availability-low

Availability for selection, not adoption
(1) "I look to different people for different things. And I think that shouldn't be ignored. Just because there's not one person that one views as a role model, you can still get a whole role model out of four different people. Maybe one person is the person you go to with all the things you're too scared to talk to anybody else about. Maybe there's somebody else you look to for, how do I handle difficult political situations, and somebody else you look to for, how do I handle this sexist stuff. Different people for different things. And I think I've gotten much more astute about that" (InMiF12, $\left.{ }_{445}\right)$.

(2) "I'm always working projects with the same kinds of people, so John is one of the account managers in Connecticut when I'm down there, but I will work projects with the other two as well. So I see three or four different styles of, here's a way to manage a project, here's a way to address this opportunity with a client, here's the kind of things they do from a client development standpoint, from a new business development standpoint, and kind of mix and match and bring my own style to bear and see where I'm comfortable" (CoMiM10, $\left.{ }_{637}\right)$.

(3) "I think I was (satisfied with available role models) as a new person. At this stage, having gotten to a certain level of success in drawing clients in and generating gross credits, right now there's not really a lot, at this stage. You're kind of on your own-there's education, there's research reviews and seminars, but that's just ideas and investment philosophy, not an example of how to run your business There's a lot in the beginning, but there's not a lot now" (InMiM9, 1045$)$.

(4) "There are other people that you know, you certainly respect and certainly enjoy conversations with and interactions with and I do ask for different opinions from different people. But there's not a real clean cut, well, here's the ideal role model for a region manager... I mean, the net of people you can go to for input has seemed to get smaller for me. Maybe that's natural, but it's also frustrating at times" $($ CoMiM12, 1136$)$.

(5) "On one level, it's more important (to have models), just because I have a much greater understanding of what a role model can or cannot do. When you're starting out, you're kind of like a puppy just following mom around; your screen, your filter really isn't very good. You can learn from the receptionist, you can learn from the partner's secretary, you can learn from anybody because they all know so much more than you do about the company. But now I would say who I have as a role model is so much more important. Because we're talking about honing skills as opposed to developing them" $\left(\right.$ InMiF12, $\left.{ }_{1322}\right)$.

(6) "I'll look to other people who in my mind do that in a very professional manner, very successful, and try to figure out, they do this, now how can I do that, given who I am and what I can do, and my own strengths and weaknesses" $\left(\right.$ InMiM10, $\left.{ }_{352}\right)$.

(7) "Now there's not the problem of either imprinting, on my part, or of adopting too much of that personality, or too much of that style. I mean, I think that once you're further along you can assert yourself and your own individuality a little bit more and still learn things from a role model. I think one of the things you learn as you mature, and sometimes this happens to people earlier rather than later and maybe some people never learn it-is that you can learn things from all kinds of people" (InMiF14, 1476$)$. of four different people" (Quote 1) and that they "mix and match" (Quote 2) the styles of different models. At this stage, respondents indicated that attending to role models became more important, because their roles and future career path were less certain and their ability to select out useful attributes took on new meaning. As one respondent put it, "I'm more conscious of them, I'm more careful on who I choose as my role models. It becomes a more conscious effort as you become smarter, and I would certainly say at eight years in the busi- ness at my experience level, they are at a critical stage" (InMiM11, 221 ).

The tendency to construe role models as increasingly specific appears to be driven by two forces. First, role models offering global traits and skills were perceived to be less available. As one respondent noted (Table 4, Quote 3), having risen to a new managerial role, there were few role models he could look to; there was a sense that there had been abundant role models to illustrate how to advance to his current level, but at this point, little guidance as to how to progress further. The sec- 
ond force is that respondents indicated that they now had a better sense of self and style, and they were thus engaged in adding specific skills to that style, refining rather than creating it anew. One respondent spoke about "honing skills" as opposed to "developing them" (Quote 5); others spoke of figuring out which skills work for them (Quote 6), and "modifying" what they learned from role models.

Middle-stage respondents were more discerning in their selection of role model attributes because they had a better sense of who they were and were thus able to "assert" themselves and their own "individuality" (Quote 7). Respondents emphasized that the process was now less one of adopting, or directly imitating skills and styles in a global way from role models, and more one of selecting specific attributes. At the same time, complicating this increasing need for models was the respondents' sense that they shouldn't be looking for them. They felt that the firms expected them to be able to rely on themselves for ideas on how to make key task transitions. As one respondent stated, "I mean, unfortunately because of my level in the firm, I'm a role model, not somebody who's supposed to be looking for a role model" $\left(\mathrm{InMiF} 12{ }_{1107}\right)$. This awareness brings an increasing sense of responsibility and a simultaneous suspicion that "I am not qualified to be a role model. I need to find one for myself first."

\section{Late-Stage Role Model Construals}

Current Concerns and Goals. As in the middle stage, late-stage respondents also primarily construed specific attributes in their role models, but their motivation for attending to them was different. First, having advanced to the highest levels of the organization that they were likely to achieve, they had less career uncertainty. Indeed, most expressed substantial satisfaction with their accomplishments, a finding consistent with research showing that job and career satisfaction tends to increase with age (Kacmar and Ferris 1989). Second, since their goals were much more proximal (that is, maintaining their current position, increasing their reputation, preparing for retirement), they were more certain about how specific role models could help achieve such goals.

The Continuing Search for Specific Skills. For many late-stage respondents, their role model construals were positive and assertive-role model skills were ripe for the picking. As one respondent noted (Table 5, Quote 2), "in different pieces" she had role models, and could look to one for group skills, another for handling process, and another for clues to client relationship building. Respondents' focus now tended to be on enhancing professional skills rather than inculcating personal attributes, and they were more likely than early- or middle-stage respondents to widen their range of potential role models. Rather than construe only hierarchically superior people as exemplars, they identified peers or subordinates and people outside the organization as role models. This tendency was partially based on structural availability: By reaching the higher levels of their organization there were fewer potential models, since there was no obvious "next step." Role models lower in the status hierarchy also provided attributes that might be unavailable in people with more experience. As one respondent noted (Quote 8), he saw "role models everywhere," particularly in new, technically proficient people entering the organization.

Increasing Awareness of Negative Attributes. The second pattern in late-stage construals was that respondents spoke more frequently and vehemently about role models possessing negative attributes: $83 \%$ of respondents at Investment and $71 \%$ of respondents at Consulting in the late stage cited negative traits in role models as aspects they attended to and potentially learned from (versus $50 \%$ and $47 \%$, respectively, in the middle stage). Respondents listed a range of such negative attributes: role models were "difficult," had "huge egos" (Quote 4), and were "domineering, autocratic, loud" (Quote 7). Respondents asserted that negative role models gave them an example of how not to act (Quote 4) and guidelines for behavior they might find negative in themselves (Quote 5).

Both of these tendencies - to identify specific and negative role model attributes - appear to be linked, in respondents' minds, to greater confidence in their own operating style. Negative role models were partially explained by a "go it alone" strategy; respondents were confident in their own approach and unconvinced that most others could provide a positive example for them. One respondent proposed a "familiarity breeds contempt" hypothesis: As an individual becomes more experienced and more familiar with the working styles and personalities of those around him or her, positive traits are acknowledged, but idols increasingly show feet of clay. At this later stage, confident of their professional identity, respondents either defined models as important to enhancing that identity or as signals of behaviors to avoid. The salience of negative role models suggested that respondents wanted to distinguish themselves from certain kinds of others, and by doing so affirm the value and uniqueness of their self-concept (see Suls and Mullen 1982). 


\section{Table 5 Example Quotes Characterizing Late-Stage Respondents' Role Models}

Dimensions:

Positive/specific attributes

of role models

Increasingly negative

Availability

Perception of role models changing over time
(1) "I'm always looking at others and so forth to see how they operate. There's certain things that you're struggling with, and how to-who are the people you can look to or go to or observe that exhibit that. Maybe it's more sort of pieces of things you're taking from people, rather than any one person" $(\mathrm{CoLaF} 15,345)$.

(2) "In different pieces I have role models. When I think about group skills, there's a consultant I work with who just has an incredible ability to handle process. So he's a role model for me from a process skills standpoint. There's another person... who really is a good role model in terms of relationship building" (CoLaF21,604).

(3) "I look for-there may be individual qualities that I see in others that I admire, and try to wear more. Whether that's among the other original managers or among any of the partners that run the business - there's no single person that's. 'That's what I want to be' " (InLaM18, $\left.{ }_{1214}\right)$.

(4) "What I do look at, is that there are some very difficult people in the firm, there are people that have huge egos, that have short tempers, you know, just all kinds of things, and what I do look at, is I look at how certain people act in terms of ways I don't want to act. And so I do look at that. I look at that a lot" (InLaF13,864).

(5) "Some of it is in the qualities of the people that I report to, that I can see how it creates problems for me. When they act in particular ways. And so I think, well I've got to make sure that I'm not doing that" (CoLaM16, 1227$)$.

(6) "They're unethical, they're slimy, they're bad people, they're self promoting, they're whatever they are. Absolutely. I probably have more anti-models (now) than I have models" (InLaF17, ${ }_{1371}$ )

(7) "I would say most of the people that I learned from within the firm were people that I didn't want to emulate-people who lack sensitivity and empathy for other people, people whose behavior was abusive, people who were domineering, autocratic, loud" (InLaM15, ${ }_{739}$ ).

(8) "I see role models everywhere. We have a lot of bright, young people who themselves, particularly in the way they can get problems solved, in the way they deal with business issues, I'm learning from them all the time. (For example), one of my associates is a Harvard MBA, and relative to financial analysis he is incredible" (CoLaM17,487).

(9) "A couple of the other people that are managing regional office and I are sort of mutual role models - I learn from them, they learn from me... And there are a few of the clients that I think do some things particularly well, that I would try to model certain portions of what I'm doing after" (InLaM18, $\left.{ }_{802}\right)$.

(10) "My role models were so, I think, heavily focused on one or two people, maybe the role model now is an aggregate of many more personalities or styles" (CoLaM21, ${ }_{1057}$ ).

(11) "I've probably shaped at least $80 \%$ of my own style, based on prior role models, of course, but I'm not particularly looking to others for role models. It's more individual ideas, or a particular process, or something. So I'm still looking for better ideas, but it's not so much role models. I think I'm more in the category of trying to be one for other people" (CoLaM17, $\left.{ }_{1791}\right)$.

(12) "I think the circle does become a little bit smaller as you get more experienced and older. There are fewer of those people that you do look to as role models, that you'd like to be like" (CoLaF18 $\left.{ }_{2129}\right)$.

\section{Discussion}

This article traces individuals' construals of their role models across the career span. It shows that individuals construe such models along dimensions of positive and negative, global and specific, close and distant, up and across/down, and that the relative importance of dimensions attended to by respondents differs depending on their career stage. Considering these dimensions is important, because role models have traditionally been considered from the point of view of the role model's actions. It was assumed that individuals' role models were essentially indistinguishable from significant others, such as parents, mentors, and leaders. However, this study suggests that role models represent a selection process among the people in organizational roles available to the individual, combined with an active cognitive 
interpretation of role model attributes (cf. Bandura 1977, 1986; Bucher and Stelling 1977; Ibarra 1999). It suggests that our attention should be focused on how individuals create role models from the people they observe rather than on the actions of the models themselves.

While previous studies have emphasized early task transitions as a motivating factor in role model construction (Ibarra 1999, Nicholson 1984), the factors underlying the transition have not been emphasized: I find that these role model constructions change depending on both the individual's perceived context-needs and goals, task responsibilities, and available role modelsand the individual's developing self-concept across the whole career. In particular, respondents' perceived availability of role models was found to be critical in how they construed their models and the certainty they felt about attaining future career goals. Though some research has examined this variable as a component of career choice (e.g., Krumboltz 1996), it deserves further research as a variable in individuals' entire career span.

This study contributes to career theory by showing that the search for role models goes on throughout individuals' careers and forms an integral part of their development. The growth depicted in traditional developmental models is toward greater coherence and stability in the self-concept (Super 1963, Kegan 1982). However, the role model construals described here support research challenging this traditional view. The fact that middle- and late-stage respondents continued to heed role models suggests that respondents still welcomed self-concept refinements. And, even as later-stage respondents exhibited increased confidence in their selfconcept, this confidence did not necessarily lead to an absence of role models. Rather, it led to lesser reliance on role models of a particular kind: positive models possessing global attributes. Role model construals did not disappear in later stages, but rather became more complex and differentiated as individuals became more selective in the attributes they observed.

\section{Explaining the Observed Patterns}

Why the Trend Towards More Specific Attributes? The finding that role model construals trend toward more specific attributes in later career (see Figure 1) is consistent with recent research and theory. First, it follows from individuals' conceptions of their possible selves across the lifespan. Studies show that the number of possible selves individuals perceive tends to decline with age (Baltes and Carstensen 1991). As individuals reach and pass the age of 40 , the possible selves they discuss tend to be less numerous, more specific, and less discrepant with their current self. They no longer picture themselves as one day being "rich and famous," but instead seek to be "comfortably retired" in a particular place (Cross and Markus 1991, p. 250). If, as Markus and Nurius (1986) suggest, role models provide exemplars of a person's possible selves, and these possible selves are becoming more specific, it follows that the attributes attended to in role models would also be more specific.

A second source of support for this pattern is a related argument suggested by the theory of socioemotional selectivity. In outlining this theory, Carstensen et al. (1999) argue that as long as individuals regard their available time as open-ended, as in the early and middle adult years, they will have a primary goal to acquire information. They will be oriented toward meeting new people and learning new skills. At middle age, as individuals begin to think of their lifespan as limited, however, they become oriented more to the present than the future, and their goals are directed toward experiencing emotional satisfaction rather than acquiring new information. This suggests that as people age, they use their social interactions less to gather new information and make new contacts and more to "defend, maintain, promote, and enhance" positive feelings and their self-concept (Baltes and Carstensen 1991, p. 259). The notion that in early stages individuals exhibit an expansive goal of acquiring information, and that in later stages they focus on preserving and enhancing what they have, reinforces a pattern of role models sought for global attributes in early stages, and more specific attributes in later stages.

Why the Trend Towards More Negative Attributes? The second prominent trend identified in Figure 1 is that individuals construe their role models as more negative in later career stages. This trend has not been extensively explored in the literature on developmental agents. In mentoring literature, for example, research has primarily emphasized the positive, yet recent studies indicate that these relationships also have potentially negative aspects (see Eby et al. 2000). Why should respondents observe more negative aspects of role models in their later career stages? One answer came directly from respondents, in the perception that as they gained confidence in their own style and had more experience, their judgment of others became more critical, less allowing of idiosyncrasies. For example, respondents in later career judged abrasive and arrogant styles in role models negatively, although they had accepted them in early stages when they had less of a standard against which to judge them. By having a better idea of what 
their self-concept was, they were better able to discern what their self-concept was not.

However, having a better idea of what was negative does not necessarily explain why they would pay attention to these negative role models; in fact, one could argue that increasing confidence in themselves might lead individuals to avoid them or regard them as irrelevant. One possible answer to this puzzle lies in the social comparison literature. Researchers have suggested that individuals have a desire to evaluate themselves against others, and they typically seek to compare themselves to similar others, so that performance can be judged most accurately (Festinger 1954). However, researchers who have examined individuals' social comparisons throughout the lifespan have asserted that the tendency to compare to similar others is attenuated after the age of 40. At this point, Suls and Mullen (1982) assert, individuals desire confirmation that they are making a special contribution and are unique in some way, and may actually prefer comparisons with dissimilar others. This research suggests that one reason that individuals identified more negative attributes in middle and late career stages is that in pointing out the negative, they were affirming the value and uniqueness of their own self-concept.

More research is needed to investigate the impact of individuals construing negative role models in individuals' work settings. Though the social comparison research cited above suggests that perceiving increasingly negative role models can be generalized, it is possible that the tendency to heed negative role model attributes was more pronounced in the highly competitive, financially oriented settings I examined. It is also worth examining how individuals are affected by attending to negative role models. Though respondents suggested that they could learn positive guidelines by observing negative actions in others, it seems likely that at some point a prevalence of negative models would hinder an individual's performance in and commitment to an organization. Under what conditions can individuals learn by observing negative role models? Are negative role models only "functional" in the middle and later stages, when the individual's self-concept is more established? What is the effect of negative role models at early stages? More research on this "dark side" of role models is needed.

\section{Limitations}

This study's findings are potentially limited by several factors. First, the study relies on a small number of respondents in the professional service context.
Identification patterns in differing organizational structures, exhibiting different organizational demographics, or organizations with differing tasks or socialization processes (Van Maanen and Schein 1979) might exhibit different role model characteristics, particularly in the timing of appropriate stages. Second, by emphasizing patterns across respondents in different career stages, homogeneity within stages may have been overemphasized (Dannefer 1987). The finding of differences between early, middle, and late career stages is not meant to suggest little or no intracohort variation, but rather that the variation across stages may provide more insight into career development. Further research should compare the level of variation both within and across stages. Third, this research may be subject to a social desirability bias. Because the term "role model" is widely known and having role models is generally considered positive, the notion may exist that individuals should have role models. This could have prompted respondents to apply this term to a greater number of people than they might have without prompting. However, the fact that several respondents ( $26 \%$ of the whole sample) indicated that they did not have positive role models suggests that social desirability did not exert a strong effect.

\section{Implications}

This study has several implications for careers and professional development. First, by understanding how individuals construe their role models, managers who are interested in developing professionals can attempt to enhance opportunities throughout individuals' careers. In the early stages of the organizations I examined, there was an appropriate match between what the organization provided in opportunities to observe role models and individuals' developmental needs. Individuals were able to observe a range of models, particularly as part of their work teams, and most were able to identify with two or three prominent exemplars. In the middle stage, however, respondents felt they lacked role models. On one hand, this may be appropriate. In the winnowing process to determine those who would succeed as partners, the firms needed to find those who could develop "on their own" without the guidance of role models. On the other hand, by fostering this developmental vacuum in the middle years, firms risk losing or misdirecting experienced talent. This study suggests that firms recognize the growth needs of middle-stage individuals by emphasizing exposure to exemplary peers and superiors. There is not a need for apprenticeship at this stage-middle-stage professionals are looking to select attributes, not to adopt another person's style - but there 
is need to expose them to others who can help them refine style and goals.

Second, it is increasingly important for managers to understand how older employees develop because the proportion of older workers will be increasing in the next 10-20 years, and the trend toward delayed retirements (to age 70, rather than 65) will only exacerbate this trend (Kacmar and Ferris 1989). While a stereotype exists suggesting that older employees are less flexible and desirous of change (Rosen and Jerdee 1985), this study finds evidence of late-stage adaptation and change. Older respondents observed role models with an interest in learning new skills and affirming the effectiveness of their already acquired skills and styles. This suggests that organizations should offer opportunities for continued, specific development throughout careers. While middle-stage individuals need exposure to role models who can help refine their style, late-stage individuals need exposure to models who can help them add specific organizational skills tied to their goals.

Finally, turbulent work environments with more rapid organization and career changes characteristic of boundaryless careers also suggests that practitioners need to rethink traditional assumptions about developmental relationships (Weick 1996). The notion that individuals will receive explicit career guidance and support from mentors is being replaced. Instead, individuals need to establish their own "network" or portfolio of developmental relationships, varying in tie strength and variety (Higgins and Kram 2001). Role models are an important part of this relationship portfolio. Because role models may be observed from a distance, and because the individual can select out attributes most useful to him or her, they may help fill a gap in an environment where traditional mentors are more difficult to find (Gibson, in press).

This study takes the first steps toward developing a career-stage framework of role models. Individuals who are motivated to succeed in a particular organization creatively and strategically select attributes from others based on their perceived similarity to individuals' most important self-concept goals and needs. Understanding how individuals' construe their role models throughout careers provides valuable insights into how individuals perceive their organizational world and how the professional self-concept develops.

\section{Acknowledgments}

The author is grateful to Senior Editor Barbara S. Lawrence and three anonymous reviewers for their careful reading and patience with this manuscript. The author thanks Sigal Barsade, Connie Gersick, Monica Higgins, Kathy Kram, Mike Pratt, and David Thomas for listening to his ideas, Kathleen Jackson for editorial help, and members of the UCLA doctoral seminar and the University of Illinois Organizational Behavior Proseminar for their encouraging comments.

\section{Endnotes}

${ }^{1}$ Age-graded life span theories (e.g., Levinson et al. 1978) and some previous mentoring studies (e.g., Kram and Isabella 1985) have used participants' age as a proxy to indicate the career stage of participants. This approach is not appropriate in this setting, because respondent perceptions of whether they were in early, middle, or late career were highly aligned with how long they had been with the firm and what their task responsibilities were, rather than age per se (though tenure and age were also highly correlated, $r=0.92$ ). Moreover, the emphasis on fairly rapid promotion (or exit) put a premium on youth so that participant ages that some studies would regard as middle career, such as 45 (e.g., Kram and Isabella 1985), are considered by these respondents to be late stage.

${ }^{2}$ Interview questions are available from the author.

${ }^{3}$ Respondent quotes are identified to indicate Investment (In) or Consulting (Co), Early (Ea), Middle (Mi), or Late (La) career stage, Male (M) or Female (F), a unique respondent number (1-21 or 22 at each site), and the line of the quote from the interview transcripts.

${ }^{4}$ I focus on the global versus specific dimension using positive attributes to reflect respondents' tendency to provide more detail about their positive role models and to mention positive role models more frequently. With negative role models, respondents were more likely to speak generally rather than to identify specific attributes. As a caveat, this tendency may have been due more to a reluctance to identify negative traits in others than indicating a general tendency about negative role models, a factor that deserves further study.

\section{References}

Ashford, S. J., L. L. Cummings. 1983. Feedback as an individual resource: Personal strategies of creating information. Organ. Behavior Human Decision Processes 32 370-398.

Ashforth, B. E. 2001. Role Transitions in Organizational Life: An Identity-Based Perspective. Erlbaum, Mahwah, NJ.

Baltes, M. M., L. L. Carstensen. 1991. Commentary on "Possible selves across the life span." Human Development 34 256-260.

Bandura, A. 1977. Self-efficacy: Toward a unifying theory of behavioral change. Psych. Rev. 84 191-215.

1986. Social Foundations of Thought and Action. Prentice Hall, Englewood Cliffs, NJ.

Bell, A. P. 1970. Role modelship and interaction in adolescence and young adulthood. Developmental Psych. 2 123-128.

Brewer, M. B. 1988. A dual process model of impression formation. T. K. Srull, R. S. Wyer, Jr., eds. Advances in Social Cognition, Vol. 1. Erlbaum, Hillsdale, NJ, 177-183.

Bucher, R., J. G. Stelling. 1977. Becoming Professional. Sage, Beverly Hills, CA.

Byrne, D. 1971. The Attraction Paradigm. Academic Press, New York.

Caldwell, D. F., J. A. Chatman, C. A. O'Reilly. 1990. Building organizational commitment: A multifirm study. J. Occupational Psych. $63245-261$.

Carstensen, L. L., D. M. Isaacowitz, S. T. Charles. 1999. Taking time seriously: A theory of socioemotional selectivity. Amer. Psychologist 54(3) 165-181.

Collins, R. L. 1996. For better or worse: The impact of upward social comparisons on self-evaluations. Psych. Bull. 119 51-69. 
Cross, S., H. Markus. 1991. Possible selves across the life span. Human Development 34 230-255.

_, M. L. Morris, J. S. Gore. 2002. Thinking about oneself and others: The relational-interdependent self-construal and social cognition. J. Personality Soc. Psych. 82 399-418.

Dalton, G. W. 1989. Developmental views of careers in organizations. M. B. Arthur, D. T. Hall, B. S. Lawrence, eds. Handbook of Career Theory. Cambridge University Press, Cambridge, U.K., 89-109.

Dannefer, D. 1987. Aging as intracohort differentiation: Accentuation, the Matthew effect, and the life course. Sociological Forum 2 211-236.

Deal, T. E., A. A. Kennedy. 1982. Corporate Cultures: The Rites and Rituals of Corporate Life. Addison-Wesley, Reading, MA.

Decker, P. J. 1982. The enhancement of behavior modeling training of supervisory skills by the inclusion of retention processes. Personnel Psych. 35 323-332.

Earley, P. C., R. Kanfer. 1985. The influence of component participation and role models on goal acceptance, goal satisfaction, and performance. Organ. Behavior Human Decision Processes 36 378-390.

Eby, L. T., S. E. McManus, S. A. Simon, J. E. A. Russell. 2000. The protege's perspective regarding negative mentoring experiences: The development of a taxonomy. J. Vocational Behavior 57 1-21.

Elsbach, K. D., C. B. Bhattacharya. 2001. Defining who you are by what you're not: Organizational disidentification and the National Rifle Association. Organ. Sci. 12 393-413.

Ely, R. J. 1994. The effects of organizational demographics and social identity on relationships among professional women. Admin. Sci. Quart. 39 203-238.

Erikson, E. H. 1985. Childhood and Society, 35th anniversary ed. W. W. Norton, New York.

Festinger, L. 1954. A theory of social comparison processes. Human Relations 7 117-140.

Fisher, B. 1988. Wandering in the wilderness: The search for women role models. Signs: J. Women Culture Soc. 13 211-233.

Fiske, S., S. E. Taylor. 1991. Social Cognition, 2nd ed. McGraw-Hill, New York.

Gecas, V., J. T. Mortimer. 1988. Stability and change in the selfconcept from adolescence to adulthood. T. Honess, K. Yardley, eds. Self and Identity: Perspectives Across the Lifespan. Routledge \& Kegan Paul, London, U.K.

Gergen, K. J. 1977. The social construction of self-knowledge T. Mischel, ed. The Self: Psychological and Philosophical Issues. Blackwell, Oxford, U.K.

M. M. Gergen. 1983. Narratives of the self. T. R. Sarbin, K. E. Scheibe, eds. Studies in Social Identity. Praeger, New York.

Gibson, D. E. In press. Role models in career development: New directions for theory and research. J. Vocational Behavior.

, D. I. Cordova. 1999. Women's and men's role models: The importance of exemplars. A. J. Murrell, F. J. Crosby, R. J. Ely, eds. Mentoring Dilemmas: Developmental Relationships Within Multicultural Organizations. Lawrence Erlbaum, Mahwah, NJ, 121-142.
Glaser, B. G., A. L. Strauss. 1967. The Discovery of Grounded Theory: Strategies for Qualitative Research. Aldine de Gruyter, New York

Gould, R. 1978. Transformations: Growth and Change in Adult Life. Simon \& Schuster, New York.

Hall, D. T. 1976. Careers in Organizations. Scott, Foresman, Glenview, IL.

1986. Breaking career routines: Midcareer choice and identity development. D. T. Hall, ed. Career Development in Organizations. Jossey-Bass, San Francisco, CA, 120-159.

Higgins, M. C., K. E. Kram. 2001. Reconceptualizing mentoring at work: A developmental network perspective. Acad. Management Rev. 26 264-288.

— D. A. Thomas. 2001. Constellations and careers: Toward understanding the effects of multiple developmental relationships. J. Organ. Behavior 22 223-247.

Hill, L. A. 1992. Becoming a Manager: Mastery of a New Identity. Penguin, New York.

Howell, D. 1992. Statistical Methods for Psychology, 3rd ed. PWSKent, Boston, MA.

Huber, G. P., W. H. Glick. 1995. Sources and forms of organizational change. G. P. Huber, W. H. Glick, eds. Organizational Change and Redesign. Oxford University Press, New York, 3-15.

Ibarra, H. 1999. Provisional selves: Experimenting with image and identity in professional adaptation. Admin. Sci. Quart. 44 764-791

Javidan, M., B. Bemmels, K. Stratton-Devine, A. Dastmalchian. 1995. Superior and subordinate gender and the acceptance of superiors as role models. Human Relations 48 1271-1284.

Jung, J. 1986. How useful is the concept of role model?: A critical analysis. J. Soc. Behavior Personality 1 525-536.

Kacmar, K. M., G. R. Ferris. 1989. Theoretical and methodological considerations in the age-job satisfaction relationship. J. Appl. Psych. 74 201-207.

Kanter, R. M. 1977. Some effects of proportion on group life: Skewed sex ratios and responses to token women. Amer. J. Soc. 82 965-990.

Katz, D., R. L. Kahn. 1978. The Social Psychology of Organizations. John Wiley \& Sons, New York.

Kegan, R. 1982. The Evolving Self: Problem and Process in Human Development. Harvard University Press, Cambridge, MA.

Kelman, H. C. 1961. Processes of opinion change. Public Opinion Quart. 25 57-78.

Kemper, T. D. 1968. Reference groups, socialization and achievement. Amer. Sociological Rev. 33 31-45.

Kohlberg, L. 1963. Moral development and identification. H. W. Stevenson, ed. Child Psychology: The Sixty-Second Yearbook of the National Society for the Study of Education (Part 1). University of Chicago Press, Chicago, IL, 277-332.

Kram, K. E. 1985. Mentoring at Work: Developmental Relationships in Organizational Life. Scott, Foresman, Glenview, IL.

, L. A. Isabella. 1985. Mentoring alternatives: The role of peer relationship in career development. Acad. Management J. 28 $110-132$. 
Krumboltz, J. D. 1996. A learning theory of career counseling. M. L. Savickas, W. B. Walsh, eds. Handbook of Career Counseling Theory and Practice. Davis-Black Publishing/Consulting Psychologists Press, Palo Alto, CA, 55-80.

Kulik, C. T., M. L. Ambrose. 1992. Personal and situational determinants of referent choice. Acad. Management Rev. 17 212-237.

Levinson, D. J., C. N. Darrow, E. B. Klein, M. H. Levinson, B. McKee. 1978. The Seasons of a Man's Life. Knopf, New York.

Lockwood, P., Z. Kunda. 1997. Superstars and me: Predicting the impact of role models on the self. J. Personality Soc. Psych. 73 91-103.

Maccoby, E. E., C. N. Jacklin. 1974. The Psychology of Sex Differences. Stanford University Press, Stanford, CA.

Manz, C. C., H. P. Sims, Jr. 1981. Vicarious learning: The influence of modeling on organizational behavior. Acad. Management Rev. 6 105-113.

Markus, H., P. Nurius. 1986. Possible selves. Amer. Psychologist 41 954-969.

, E. Wurf. 1987. The dynamic self-concept: A social psychological perspective. Annual Rev. Psych. 38 299-337.

Merton, R. K. 1968. Social Theory and Social Structure, rev. ed. Free Press, New York.

Nicholson, N. 1984. A theory of work role transitions. Admin. Sci. Quart. 29 172-191.

Ostroff, C., S. W. J. Kozlowski. 1992. Organizational socialization as a learning process: The role of information acquisition. Personnel Psych. 45 849-874.

Rosen, B., T. H. Jerdee. 1985. Older Employees: New Roles for Valued Resources. Dow Jones-Irwin, Homewood, IL.

Schein, E. H. 1978. Career Dynamics: Matching Individual and Organizational Needs. Addison-Wesley, Reading, MA.

Shapiro, E. C., F. P. Haseltine, M. P. Rowe. 1978. Moving up: Role models, mentors, and the "patron-system." Sloan Management Rev. 19 51-58.

Slater, P. 1961. Toward a dualistic theory of identification. MerrillPalmer Quart. 7 113-126.

Speizer, J. J. 1981. Role models, mentors, and sponsors: The elusive concepts. Signs: J. Women Culture Soc. 6 692-712.

Spradley, J. P. 1979. The Ethnographic Interview. Holt, Rinehart and Winston, New York.

Suls, J., B. Mullen. 1982. From the cradle to the grave: Comparison and self-evaluation across the life span. J. Suls, ed. Psychological Perspectives on the Self, Vol. 1. Erlbaum, Hillsdale, NJ, 97-128.

Super, D. E. 1963. Career Development: Self-Concept Theory. College Entrance Examination Board, New York.

. 1980. A life-span, life-space approach to career development. J. Vocational Behavior 13 282-298.

Thomas, D. A. 1990. The impact of race on manager's experiences of developmental relationships (mentoring and sponsorship): An intra-organizational study. J. Organ. Behavior 11 479-492.

Vaillant, G. E. 1977. Adaptation to Life. Little, Brown, Boston, MA.

Van Maanen, J., E. H. Schein. 1979. Toward a theory of organizational socialization. B. M. Staw, ed. Research in Organizational Behavior, Vol. 1. JAI Press, Greenwich, CT, 209-264.

Weick, K. E. 1996. Enactment and the boundaryless career: Organizing as we work. M. B. Arthur, D. M. Rousseau, eds. The Boundaryless Career, Vols. 40-57. Oxford, New York.

Weiss, H. M. 1977. Subordinate imitation of supervisory behavior: The role of modeling in organizational socialization. Organ. Behavior Human Performance 19 89-105.

Wood, J. V. 1996. What is social comparison and how should we study it? Personality Soc. Psych. Bull. 22 520-537.

Wood, R., A. Bandura. 1989. Social cognitive theory of organizational management. Acad. Management Rev. 14 361-384. 